\title{
Predictive and Prognostic Markers in Breast Cancer Treatment - Presentations at the 28th San Antonio Breast Cancer Symposium 2005
}

\author{
Achim Rody Thomas Karn Manfred Kaufmann \\ Department of Obstetrics and Gynecology, Johann Wolfgang Goethe University, Frankfurt, Germany
}

\section{Key Words}

Markers, prognostic and predictive - Therapy: adjuvant, neoadjuvant, endocrine $\cdot$ Breast cancer

\section{Summary}

The increasing understanding of the pathophysiological background of breast cancer is associated with new molecular techniques, improved risk assessment, targeted therapy and individualized treatment. Gene expression profiling may provide predictive and prognostic gene signatures which could help characterize tumors and enable more tailored therapies. Beyond this, gene expression profiling allows us to better understand tumor development and can help identify new molecular markers which should be investigated in terms of specific clinical objectives. There is also an increasing trend towards translational research in large clinical trials which gives new insight into pathophysiology and the prediction of response according to specific therapeutic approaches. Even if the detection of new molecular markers gives rise to new hypotheses, most studies lack a prospective setting, and thus the use of identified markers or specific gene signatures in clinical routine is still limited.

\section{Schlüsselwörter}

Marker, prognostische und prädiktive - Therapie: adjuvante, neoadjuvante, endkorine $\cdot$ Mammakarzinom

\section{Zusammenfassung}

Das wachsende Verständnis um die pathophysiologischen Zusammenhänge von Brustkrebs ist eng mit der Entwicklung neuer molekularer Techniken, der Verbesserung der individuellen Einschätzung des Krankheitsrisikos sowie der Verfügbarkeit zielgerichteter Therapien und individualisierter Therapiekonzepte verbunden. Genexpressionsanalysen sind in der Lage, prognostische und prädiktive Gensignaturen zu liefern, die einerseits die Tumorcharakterisierung, andererseits die zielgerichtete Therapie optimieren können. Darüber hinaus helfen Genexpressionsanalysen, Einblicke in die Tumorentstehung zu erhalten und neue molekulare Marker zu identifizieren, die dann Gegenstand weiterer klinischer Untersuchungen sind. Der zunehmende Trend, translationale Forschungsprogramme im Rahmen großer klinischer Studien voranzutreiben, liefert des Weiteren neue Einblicke in pathophysiologische Zusammenhänge sowie die Vorhersage des Ansprechens auf spezifische Therapiemaßnahmen. Auch wenn die Identifizierung molekularer Marker durchaus neue Hypothesen generieren kann, sind allerdings viele Studien nicht prospektiv ausgerichtet, so dass der routinemäßige klinische Einsatz zahlreicher Marker limitiert ist.

\begin{tabular}{ll}
\hline KARGER & @ 2006 S. Karger GmbH, Freiburg \\
$\begin{array}{l}\text { Fax +49 761452 07 14 } \\
\begin{array}{l}\text { E-mail Information@Karger.de } \\
\text { www.karger.com }\end{array}\end{array}$ & $\begin{array}{l}\text { Accessible online at: } \\
\text { www.karger.com/brc }\end{array}$ \\
&
\end{tabular}




\section{Introduction}

Decision-making in adjuvant or palliative therapy of breast cancer is not only determined by assessing individual risk and prognosis but also by evaluating if corresponding targets are present which may predict treatment efficacy in a more precise way. As a consequence, the establishment of biological markers and the implementation of translational research is an incremental part of clinical trials.

\section{Predictive and Prognostic Markers in Adjuvant Cytotoxic Treatment of Breast Cancer}

Anthracycline-containing chemotherapy is one of the most effective treatment options for both adjuvant and metastatic breast cancer. However, a significant proportion of patients have a pre-existing or acquired anthracycline resistance and therefore do not benefit from such compounds. Many efforts have been undertaken to identify patients with anthracyclineresistant breast cancer, and there is growing evidence that topoisomerase II $\alpha$ (topo II $\alpha$ ) is one of the most important markers in this context. Slamon et al. [1] presented the first interim analysis of the Breast Cancer International Research Group (BCIRG) 006 study, which investigated 3 different chemotherapy regimens: i) $4 \times \mathrm{AC} \rightarrow 4 \times \mathrm{T}$; ii) $4 \times \mathrm{AC} \rightarrow 4 \times$ $\mathrm{TH}$; iii) $6 \times \mathrm{TCcH}(\mathrm{A}=$ doxorubicin, $\mathrm{C}=$ cyclophosphamide, $\mathrm{T}=$ docetaxel, $\mathrm{H}=$ trastuzumab, $\mathrm{Cc}=$ carboplatin) for 1 year in 3,222 HER2-positive breast cancer patients. Both trastuzumab-containing treatment arms showed a significant benefit in terms of disease-free survival (DFS). Furthermore, the authors presented a subgroup analysis of the HER2 amplicon with topo II $\alpha$ amplification in 17q21.2 as a marker for better response to anthracycline-containing chemotherapy: in 35\% (744 of 3,222) of all patients treated within this study co-amplification of topo II $\alpha$ was demonstrated. Relating to all patients, in the subgroup with detectable topo II $\alpha$ co-amplification DFS was significantly higher than in patients without coamplification (57 vs. 191 events, $\log$ rank $\mathrm{p}<0.001$ ). Stratification by treatment arm in the subgroup with co-amplification showed no significant differences $(\log$ rank $p=0.24)$, but a trend in favor of $\mathrm{AC} \rightarrow \mathrm{TH}$ was seen. In summary, the authors conclude that in the subgroup with co-amplification of HER2 and topo II $\alpha$, treatment with an anthracycline-based trastuzumab combination might be beneficial. HER2-positive patients without topo II $\alpha$ co-amplification (approximately $65 \%$ ) do not appear to have the same benefit and may be ideal candidates for efficacious, non-anthracycline-based regimens, thus avoiding potential cardiotoxicity.

The classification of breast cancer according to Sorlie et al. [2] revealed 5-6 different subgroups associated with a distinct prognosis. Within these subgroups, basal-like tumors constitute the worst prognosis. However, it still remains unclear whether this classification is of further predictive value, e.g. in terms of cytotoxic drug therapy. In a retrospective analysis of 49 patients with basal-like breast cancer and 49 matched-controls, Banerjee et al. [3] investigated if anthracycline-based adjuvant chemotherapy is an effective chemotherapy regimen in this subgroup. The authors was able to demonstrate that anthracycline-based chemotherapy is less effective in basallike tumors, since DFS and overall survival (OS) showed significant differences. However, the multivariate analysis including estrogen receptor (ER), progesterone receptor (PR), lymphovascular invasion, endocrine therapy and basal-like status reached no statistical significance, which can be attributed to the small number of patients analyzed. The authors conclude that new treatment options (e.g. platinum-based chemotherapy) should be investigated for this subtype of breast cancer.

While activation of c-myc is associated with an increased rate of apoptosis [4], HER2 amplification seems to antagonize the pro-apoptotic effect of activated c-myc and lead to breast cancer with a high proliferation rate. Trastuzumab might inhibit the anti-apoptotic effect of HER2 amplification. Kim et al. [5] presented data from the National Surgical Adjuvant Breast and Bowel Project (NSABP) B28 $(\mathrm{n}=1,901)$ trial demonstrating that amplification of c-myc or HER2 is associated with a poor prognosis. In tumors with no amplification, the 5-year recurrence rate has been established at $19.17 \%$. However, it increases to as much as $29.5 \%$ if amplification of c-myc or HER2 is present. The prognosis is even worse when both genes are co-amplified (5-year recurrence rate of $40.17 \%$ ). Based on this observation, the authors investigated c-myc coamplification in HER2-positive tumors in patients enrolled in the NSABP B31 trial $(\mathrm{n}=1,549)$. Co-amplification was defined as $>5$ average hybridization signals per nucleus measured by fluorescence in situ hybridization (FISH) analysis in tissue microarray. In this HER2-positive cohort, a proportion of c-myc co-amplification of $30.4 \%$ was observed. Patients without c-myc amplification treated with trastuzumab had a statistically significant better outcome in terms of time to first recurrence than those who received no trastuzumab (hazard ratio $(\mathrm{HR}) 0.63,2 \mathrm{p}=0.007)$. However, this benefit was much higher in tumors with c-myc co-amplification (HR 0.24, $2 p<0.0001)$. The authors conclude that HER 2 overexpression presumably inhibits the pro-apoptotic effect of c-myc, resulting in an unfavorable prognosis. The administration of trastuzumab seems to abrogate the inhibition and re-initiate apoptosis in these tumors with co-amplification.

$50 \%$ of all primary breast cancers are node-negative, and $60-70 \%$ of these patients are cured by surgical treatment alone, implicating that $30-40 \%$ do not need any adjuvant therapy. To date, the identification of patients with high-risk disease and subsequently the provision of suitable adjuvant therapy is an ongoing controversy. In this context, the establishment of a prognostic gene signature for risk determination of node-negative breast cancer patients is an important issue. Foekens et al. [6] demonstrated validation data of a 76-gene 
prognostic signature. The training set comprised 286 patients and revealed 76 genes encompassing prognostic signature. The authors first introduced the validation data of 171 patients in a single center with a median follow-up of 101 months and demonstrated that patients with a poor signature $(n=112)$ had a statistically significant worse outcome in terms of metastasis-free survival compared to those with a good signature (n = 59) $($ HR 5.67, 95\% CI 2.59-12.4, p = 9.5 × 10-7). Furthermore, a multicenter validation study with 180 patients likewise demonstrated a significant difference in patients with a poor signature $(\mathrm{n}=102)$ compared to patients with a good signature $(\mathrm{n}=78)\left(\mathrm{HR} 7.41,95 \%\right.$ CI 2.63-20.9, $\left.\mathrm{p}=8.5 \times 10^{-6}\right)$. Hence, $94 \%$ of patients with a good signature were free from metastasis at 10 years compared to $65 \%$ with a poor signature. In a multivariate analysis including age, menopausal status, tumor size, grading and ER status, the 76-gene signature was the only significant parameter for metastasis-free survival. A further multicenter analysis in which 79 patients with ER-positive, node-negative breast cancer were enrolled confirmed the prognostic value of this signature. The authors concluded that the 76-gene signature is applicable to all lymph node-negative breast cancer patients, irrespective of age, menopausal status, tumor size, grade and steroid hormone receptor status.

Cyclin E2 was part of 2 molecular signatures designed for the identification of node-negative patients with low risk of recurrence [7, 8]. Schmidt et al. [9] investigated mRNA expression of cyclin E2 in 201 untreated, node-negative breast cancer patients and compared the expression level with metastasis-free survival. Cox regression analysis revealed that cyclin E2 $(\mathrm{p}=0.001)$ and histological grading $(\mathrm{p}<0.001)$ were significantly associated with the development of distant failure. However, in multivariate analysis, only the histological grade remained significant $(\mathrm{p}<0.001)$, which challenges earlier reports of an independent association between cyclin E2 and prognosis. The prognostic value of cyclin E2 was higher in ER$\alpha$ (ESR1)-positive than in ESR1-negative tumors.

\section{Predictive Markers for Primary Systemic Chemotherapy Based on Gene Expression Profiling}

To date, many efforts have been made to detect specific marker genes for predicting tumor response and prognosis. Global gene expression profiling by microarrays has been used to identify prognostic marker genes. Gene expression analysis in breast cancer patients undergoing neoadjuvant chemotherapy is an interesting tool for the detection of gene signatures or new markers suitable to predict tumor response. Pusztai et al. [10] investigated gene expression profiling for a marker discovery associated with pathological complete remission (pCR) after 12 preoperative cycles of paclitaxel weekly followed by 4 cycles of 5-fluorouracil, doxorubicin and cyclophosphamide chemotherapy. Fine needle aspirations were obtained from 82 patients with stage I-III breast cancer for gene expression analysis using Affymetrix U133A chips (Affymetrix, Santa Clara, CA, USA). The authors identified a marker set of 31 differentially expressed probes between $\mathrm{pCR}$ and residual disease with a false discovery rate of $0.5 \%$. In a 5 -fold true cross validation by diagonal linear discriminant analysis, a 30-probe classifier proved to be the best predictor (sensitivity $75 \%$, specificity $73 \%$, positive predictive value (PPV) $50 \%$ and negative predictive value (NPV) $90 \%$ ). Furthermore, the authors demonstrated that many different multi-gene predictors of response can be developed, each showing good performance in cross validation. Still a matter of debate is the question of the optimal sample size when establishing a predictive marker set. The authors performed a learning curve and concluded that 80-100 cases can yield predictors that operate close to a projected plateau of accuracy. Nevertheless, the validation of the 30 -probe predictor is outstanding.

Schneeweiss et al. [11] also performed gene expression profiling using the Operon Human Oligo Set 2.1 (Operon, Alameda, CA, USA), comprising 21,329 gene-specific 70mers, in primary breast cancer patients receiving neoadjuvant chemotherapy with gemcitabine, epirubicine and docetaxel, either in combination or as dose-dense sequential therapy. Comprehensive RNA expression analysis was started with a training set of 50 patients, and the results were validated with an independent test set of 48 patients. The authors revealed a 512-gene signature which showed a sensitivity of $78 \%$, specificity of $90 \%$, PPV of $64 \%$ and NPV of $95 \%$. This signature encompasses genes of the TGF- $\beta$ pathway, RAS signaling, DNA damage response and apoptotic pathways. Validation of selected candidate genes by reverse transcription polymerase chain reaction (RT-PCR) showed a good correlation with the microarray data. Furthermore, the authors demonstrated that the gene expression signature is independent of conventional predictive parameters. However, beyond the described signature, HER2 was an independent predictor of pCR.

Likewise, our group [12] presented predictive gene signatures for response to neoadjuvant chemotherapy with combinations of docetaxel, doxorubicine and cyclophosphamide from gene expression profiling within the GEPARTRIO trial. 50 Patients with histologically confirmed breast cancer were enrolled in this study. Gene expression analysis was performed from core cut biopsies using the Affymetrix U133A microarrays. We analyzed tumors according to the classification described by Sorlie et al. [2] and compared these results with several clinicopathological data. Neither menopausal status, tumor stage, nodal status nor histopathological grading showed significant differences in the normal-like, basal-like, erbB 2 or luminal cluster. The histopathological grading revealed a high proportion $(68 \%)$ of intermediate-grade tumors. However, in a further analysis, 'genomic grading' as proposed by Sotiriou et al. [13] splits the tumors into well and poorly differentiated types. A high genomic grade was detectable in $90 \%$ of basal-like tumors and in $100 \%$ of erbB2 tumors ( $p<0.0001$ each). Interestingly, most cases of pCR were observed in the erbB2+ sub- 
group $(5 / 8,62.5 \% ; \mathrm{p}=0.024)$, and this subgroup also contained the highest number of clinical responders (90.9\%). In contrast, relapse during follow-up was mainly observed in the basal-like and normal-like subgroup and not in the erbB2+ subgroup. Furthermore, our analyses resulted in a marker set encompassing 90 genes allowing the identification of all cases of stable and progressive disease and the discrimination of all pCRs.

\section{Predictive and Prognostic Markers in Endocrine Treatment of Breast Cancer}

Prediction of response is an important issue not only in terms of cytotoxic drug therapy but also for endocrine treatment. Goetz et al. [14] retrospectively investigated the predictive power of homeobox 13 (HOXB13) and interleukin 17B receptor (IL-17BR) in 206 women receiving adjuvant tamoxifen with a median follow-up of 11 years. Paraffin-embedded tumor tissue was laser-microdissected, and real time PCR was performed after RNA extraction to evaluate expression of both markers. Patients with a HOXB13/IL-17BR ratio of $>-1.849(\mathrm{n}=84)$, experienced significantly worse relapse-free survival, DFS and OS. This observation was independent of routine prognostic markers, such as ER, PR, HER2, tumor grade, tumor size and nodal status. The HOXB13/IL-17BR ratio showed best performance in the node-negative subgroup and predicted survival in the univariate $(\mathrm{p}<0.0001)$, multivariate (HR 2.4, 95\% CI 1.19-4.84, p = 0.014) and multivariate (HR 2.01, 95\% CI 1.02-3.99, $\mathrm{p}=0.045$ ) cross validation analysis. Interestingly, no events were observed in the lymph nodenegative cohort with a HOXB13/IL-17BR ratio of $<-1.34$ within the first 2 years of follow-up. The authors conclude that patients who are identified as being at risk might benefit from endocrine therapy with upfront aromatase inhibitors and/or chemotherapy.

Adjuvant endocrine therapy for hormone receptor-positive breast cancer is a mandatory tool for all patients, irrespective of menopausal status. However, approximately $30-40 \%$ of all patients experience relapse with subsequent metastatic disease and death. Furthermore, about $5-10 \%$ of patients with ER- $\alpha$-negative disease respond to tamoxifen treatment. In this context, it is important to find markers which help to identify patients who are at risk and possibly do or do not benefit from endocrine treatment. Gruvberger-Saal et al. [15] presented a study investigating the prognostic role of ER- $\beta$ in 105 ER- $\alpha$-negative and 248 ER- $\alpha$-positive breast cancer patients receiving adjuvant tamoxifen for 2 years. The role of ER- $\beta$ in tamoxifen response is still unclear, particularly with regard to the fact that tamoxifen binds to ER- $\beta$ with similar affinity as ER- $\alpha$. In addition to ER- $\beta$ immunostaining, the authors demonstrated gene expression profiles of tumors which are
ER- $\alpha$-negative and were clustered for ER- $\beta$ status. Patients with strong ER- $\beta$ expression showed a significant favorable distant DFS compared to those who were moderately positive or negative for ER- $\beta(\log$ rank $\mathrm{p}=0.01)$. This was exclusively observable in ER- $\alpha$-negative but not ER- $\alpha$-positive tumors, indicating that ER- $\beta$ is a marker for a favorable prognosis in this subgroup (multivariate analysis ER- $\beta$-negative vs. ER- $\beta$ positive: HR 14, 95\% CI 1.8-106, $\mathrm{p}=0.01$ ). The authors could demonstrate that a misclassification of ER- $\alpha$ is not causal for this. Gene expression analysis of ER- $\alpha$-negative tumors by hierarchical clustering according to ER- $\beta$ expression revealed a signature with differentially expressed genes in each subgroup. The authors conclude that ER- $\beta$ has prognostic value in ER$\alpha$-negative breast cancer, and hence, ER- $\alpha$-negative/ER- $\beta$ positive tumors might benefit from endocrine treatment with tamoxifen.

Histopathological grading of breast cancer is a well established factor for risk evaluation of disease. However, approximately $40 \%$ of all tumors show an intermediate-grade classification with high interobserver variability and resulting difficulties in clinical decision making. At the annual meeting of the American Society of Clinical Oncology (ASCO) 2005, Sotiriou et al. [13] demonstrated that approximately one half of all intermediate-grade tumors were well differentiated, while the other half was poorly differentiated by genomic grading. The same author presented a study investigating if tumors classified by luminal subtype according to Sorlie et al. [2] can be better defined by genomic grading, and correlated the resulting subtypes with clinical outcome [16]. Overall, 787 ERpositive/luminal subtypes with gene expression profiles have been enrolled in this analysis. Applying genomic grade to Sorlie molecular subtypes revealed 2 different subgroups in luminal tumors (L1, L2) which showed statistically distinct clinical outcomes in both untreated and tamoxifen-treated populations. In multivariate analysis of 417 ER-positive, untreated breast cancers, genomic grade as well as tumor size showed significant value, whereas in ER-positive, tamoxifen-treated tumors, genomic grade was significant in terms of prognosis. The authors conclude that these subtypes may provide a new stratification for upcoming breast cancer trials and further individualization of treatment.

\section{Conclusion}

In conclusion, there is growing evidence that molecular characterization of breast cancer may be an interesting tool of classifying tumors in terms of prognosis and predicting specific therapeutic agents. However, most studies lacked a prospective approach. Hence, validation of the actual impact of these markers in prospective trials is necessary to estimate whether they are ready to be applied in clinical routine. 


\section{References}

1 Slamon D, Eiermann W, Robert N, Pienkowski T, Martin M, Pawlicki M, Chan M, Smylie M, Liu M, Falkson C, Pinter T, Fornander T, Shiftan T, Valero V, Mackey J, Tabah-Fisch I, Buyse M, Lindsay MA, Riva A, Bee V, Pegram M, Press M, Crown J, on behalf of the BCIRG 006 Investigators: Phase III randomized trial comparing doxorubicin and cyclophosphamide followed by docetaxel $(\mathrm{AC} \rightarrow \mathrm{T})$ with doxorubicin and cyclophosphamide followed by docetaxel and trastuzumab $(\mathrm{AC} \rightarrow \mathrm{TH})$ with docetaxel, carboplatin and trastuzumab $(\mathrm{TCH})$ in HER-2 positive early breast cancer patients: BCIRG 006 study. Breast Cancer Res Treat 2005;94 (suppl 1):abstr 1.

2 Sorlie T, Perou CM, Tibshirani R, Aas T, Geisler S, Johnsen H, Hastie T, Eisen MB, van de Rijn M, Jeffrey SS, et al.: Gene expression patterns of breast carcinomas distinguish tumor subclasses with clinical implications. Proc Natl Acad Sci U S A 2001;98: 10869-10874.

3 Banerjee SN, Reis-Filho JS, Ashley S, Steele D, Ashworth A, Lakhani S, Smith IE: Basal-like breast carcinomas: clinical outcome with chemotherapy. Breast Cancer Res Treat 2005;94(suppl1): abstr 3005 .

4 Pelengaris S, Khan M, Evan GI: Suppression of Myc-induced apoptosis in beta cells exposes multiple oncogenic properties of Myc and triggers carcinogenic progression. Cell 2002;109:321-334.

5 Kim C, Bryant J, Horne Z, Geyer CE, Wickerham DL, Wolmark N, Paik S: Trastuzumab sensitivity of breast cancer with co-amplification of HER2 and cMYC suggests pro-apoptotic function of dysregulated cMYC in vivo. Breast Cancer Res Treat 2005; 94(suppl 1):abstr 46.
6 Foekens JA, Atkins D, Sweep CGJ, Harbeck N, Paradiso A, Cufer T, Eppenberger S, Daxenbichler G, Kotzsch M, Sieuwerts AM, Talantov D, Timmermans M, Span PN, Tjan-Heijnen VCG, Specht K, Mangia A, Wight E, Angerer J, Zito AF, Hoefler H, Berns EMJ, Golouh R, Barreton G, Schittulli F, Schmitt M, Beex LVA, Klijn JGM, Wang Y: Multicenter validation of the 76-gene prognostic signature in lymph node negative (LNN) primary breast cancer. Breast Cancer Res Treat 2005;94(suppl 1): abstr 28.

7 Van't Veer LJ, Dai H, van de Vijver MJ, He YD, Hart AA, Mao M, Peterse HL, van der Kooy K, Marton MJ, Witteveen AT, Schreiber GJ, Kerkhoven RM, Roberts C, Linsley PS, Bernards R, Friend SH: Gene expression profiling predicts clinical outcome of breast cancer. Nature 2002;415: 530-536.

8 Wang Y, Klijn JG, Zhang Y, Sieuwerts AM, Look MP, Yang F, Talantov D, Timmermans M, Meijervan Gelder ME, Yu J, Jatkoe T, Berns EM, Atkins D, Foekens JA: Gene-expression profiles to predict distant metastasis of lymph-node-negative primary breast cancer. Lancet 2005;365:671-679.

9 Schmidt M, Glawatz C, Gehrmann MC, Puhl A, von Toerne C, Steiner E, Boehm D, Koelbl H: Cyclin E2 mRNA expression and metastasis-free survival in untreated node-negative breast cancer patients. Breast Cancer Res Treat 2005;94(suppl 1): abstr 3048.

10 Pusztai L, Hess KR, Gold DL, Anderson K, Ross JS, Valero V, Hortobagyi GN, Symmans WF: Affymetrix gene chip profile predicts pathologic complete response to preoperative paclitaxel/FAC chemotherapy in breast cancer. Breast Cancer Res Treat 2005;94(suppl 1):abstr 306
11 Schneeweiss A, Thuerigen O, Toedt G, Warnat P, Hahn M, Schuetz F, Lauschner I, Benner A, Brors B, Sinn H-P, Sohn C, Lichter P: Transcriptional profiling can predict the achievement of a pathologic complete response (pCR) after preoperative chemotherapy (PST) with gemcitabine (G), epirubicin (E) and docetaxel (Doc) in primary breast cancer (PBC) with high accuracy. Breast Cancer Res Treat 2005;94(suppl 1):abstr 307.

12 Rody A, Karn T, Munnes M, von Minckwitz G, Loibl S, Gaetje R, Solbach C, Holtrich U, Kaufmann M: Predictive gene signatures for response to neoadjuvant TAC-chemotherapy from expression profiling. Breast Cancer Res Treat 2005;94(suppl 1):abstr 5046.

13 Sotiriou C, Wirapati P, Loi S, Desmedt C, Harris AL, Bergh J, Smeds J, Cardoso F, Delorenzi M, Piccart M: Molecular characterization of clinical grade in breast cancer $(\mathrm{BC})$ challenges the existence of 'grade 2' tumors. J Clin Oncol 2005;23(suppl):16S (abstr 506).

14 Goetz MP, Suman VJ, Ingle JN, Nibbe AM, Visscher DW, Reynolds C, Lingle WL, Erlander MG, Ma XJ, Sgroi DC, Perez EA, Couch FJ: A two-gene expression ratio of HOXB13 and IL-17BR for prediction of recurrence and survival in women receiving adjuvant tamoxifen. Breast Cancer Res Treat 2005; 94(suppl 1):abstr 312.

15 Gruvberger-Saal SK, Bendahl PO, Saal LH, Laakso M, Eden P, Peterson C, Malmstrom P, Isola J, Borg A, Ferno M: Estrogen receptor-beta has favorable independent prognostic value for estrogen receptor-alpha negative breast cancer patients receiving adjuvant tamoxifen. Breast Cancer Res Treat 2005; 94(suppl 1):abstr 35

16 Sotiriou C, Wirapati P, Loi S, Desmedt C, Durbecc V, Harris A, Bergh J, Smeds J, Haibe-Kains B, Larsimont D, Cardoso F, Buyse M, Delorenzi M, Piccart M: Better characterization of estrogen receptor (ER) positive luminal subtypes using genomic grade. Breast Cancer Res Treat 2005;94 (suppl 1): abstr 37 